\title{
Algumas reflexões sobre vingança e antropofagia como modelos político e estéticos ainda vigentes na cultura brasileira ${ }^{1}$
}

\section{Prof. Dra. Marta Lúcia Pereira Martins DAP-CEART-UDESC ${ }^{2}$}

As aventuras do artilheiro alemão Hans Staden no período colonial brasileiro, ilustram os desígnios e as engendrações da diferença e da alteridade. Autor dos primeiros registros de viagens escritos sobre o Brasil cuja primeira versão em livro impresso foi feita em Marburg, na Alemanha, em 1557, Primeiros registros escritos e ilustrados do Brasil e seus habitantes ${ }^{3}$ descreve as duas viagens ao "Brasil" e consta entre as primeiras narrativas de testemunho dos viajantes europeus ao Novo Mundo. Nele, Staden conta a sua detenção de nove meses entre os Tupinambás onde viveu a experiência de ser ameaçado constantemente de ser objeto de antropofagia ritual. Ao longo de quatro séculos, a antropofagia havia se tornado um elemento interditado tanto no discurso "culto" do país, quanto dentro da própria cultura indígena, postando-se, porém, no primeiro movimento modernista com a voracidade com a qual todo objeto reprimido retorna. Nossa vera ícon, a face que mostramos, é sempre aquela pela qual somos vistos no jogo de espelhos cujo objetivo é o de capturar máscaras de identidade. Ao se reconsiderar, algumas das bases com as quais o modernismo antropofágico brasileiro da geração de 22, tratou de sustentar seu modelo estético baseado no motivo da vingança, se pode ver que isso implica numa condição política que de cunho pedagógico dirigida a uma invenção da identidade brasileira, que se baseia justamente na falta desta identidade. A rápida apreensão e recriação, ao nosso modo, dos modelos culturais do estrangeiro, misturadas ás manifestações regionais próprias do país, ainda permanecem como um “modo de fazer" peculiar e próprio da estética brasileira

O Manifesto antropófago postulava já na primeira linha, que: "Só a antropofagia nos une. Socialmente. Economicamente. Filosoficamente." ${ }^{4} \mathrm{Ou}$ seja, esse modelo de apreensão e de devoração era visto por Oswald como a "única coisa a unir a diversidade do país. O processo de profundas e complexas transformações que foram

\footnotetext{
${ }^{1}$ Artigo produzido a partir do Projeto de Pesquisa “ Raízes antropofágicas: labirintos e paradoxos na constituição formativa do modernismo brasileiro.

${ }^{2}$ Professora do Departamento de Artes Plásticas e coordenadora do Projeto de Pesquisa. CEART-UDESC

${ }^{3}$ STADEN, Hans. Primeiros registros escritos e ilustrados do Brasil e seus habitantes. SP: Terceiro

Nome, 1999. O estado de latência do "Brasil" de Hans Staden é contemporâneo dos primeiros núcleos europeus nesta parte meridional das Américas.

${ }^{4}$ De ANDRADE, Oswald. Manifesto Antropófago. In: SCHWARTZ, Jorge. Vanguardas Latino-

Americanas. Polêmicas, manifestos e textos críticos. SP: Iluminuras/Edusp/ Fapesp, 1995.
} 
delineando o Brasil como Estado e Nação desde os primeiros contatos e, que se abre a partir das primeiras percepções da própria paisagem e da incomensurável e abismática sensação de estranheza, que iria engendrar uma máquina produtora de alteridade entre as diferentes origens, definiria uma condição cultural de cunho múltiplo, já na formação do Brasil.

Nos primeiros registros de viagens escritos por Staden a problemática da vingança como motor cultural das culturas indígenas, aparece com frequiência e traz como conseqüência última o canibalismo. De algum modo, o motivo da vingança, que se encontra antes e por trás do ato antropofágico em si mesmo, é revivido transfigurado e metaforicamente na cultura brasileira. Longe estão os dias em que como no relato de Staden, a antropofagia ritual era fato:

\section{Porque comem seus inimigos}

Não fazem isto para saciar sua fome, mas por hostilidade e muito ódio, e quando estão guerreando uns contra os outros, gritam cheios de ódio: debe mara pá, xe remiu ram begué, sobre você abata-se toda desgraça, você será minha comida. Nde akanga juká aipotá kurine, eu ainda quero esmagar tua cabeça hoje. Xe anama pepika re xe aju, estou aqui para vingar em você a morte de meu amigo. Ndée rôo, xe mokaen será kuarisy ar eyma riré etc...tua carne será, ainda hoje, antes que o sol se ponha, o meu assado. Tudo isso, fazem-no por grande inimizade. $^{5}$

Antes de darmos um resumo das aventuras de Staden, vale pautar que o jovem artilheiro de Hessen, iria estar duplamente implicado no motivo da vingança. Por um lado, por sua bem conhecida detenção entre os tupinambás com a constante ameaça de sua devoração; mas por outro, através de sua própria vingança, que se efetivaria pela fuga e pelo relato escrito em forma de testemunho. Esta situação, que no caso de Staden se dá como um importante evento histórico, seria elaborada posteriormente, pela ficção, na literatura romântica no século XIX.

Com efeito, há uma recorrência temática no romantismo, do herói sofredor, que ao final de uma longa série de percalços durante a maior parte da vida (dificuldades que são enfrentadas pela certeza da vingança final), triunfa, abrindo mão, de modo magnânimo, dos propósitos vingadores longamente cultivados durante o tempo de ${ }^{5}$ STADEN, Hans. Op Cit, p.104. 
sofrimento, que geralmente alimenta a sobrevivência do herói.. A esse respeito, o crítico literário Antônio Cândido dedicou um ensaio, "Da Vingança", ${ }^{6}$ onde analisa a figura do Conde de Monte Cristo, de Alexandre Dumas. Embora os ensaios de Candido neste livro sejam uma compilação de publicações anteriores, em sua maioria, datados da década de 50, merece atenção o fato de que os títulos e algumas imagens escolhidas pelo autor para desenvolver suas análises, possam ser, sugestivamente, lidos como uma escolha muito pontual em relação ao que poderia e não poderia ser dito, no contexto da ditadura militar. ${ }^{7}$ Mas, no que diz respeito à discussão mais propriamente literária no ensaio de Candido sobre a temática da vingança, é visível que em sua análise do Conde, ele a defina como parte de um certo, "temário romântico, do egotismo, do satanismo, da vontade de poder, da solidão, cosidos em torno da dialética do bem e do mal"", suprimindo qualquer menção à antropofagia, o que poderia nos levar a entender, que talvez nos encontremos diante de uma alusão, feita por ausência, à aspectos da "conduta burguesa", de nossos vingadores estético-culturais: os modernistas de 22 .

Se resumirmos a ampla análise de Candido - grifando apenas alguns aspectos que nos interessam para ampliar a maneira com a qual estamos aqui fazendo referência ao tema da vingança, vemos que o autor aponta, justamente, ao caráter pessoal desta na estética romântica. E indo além ele atribui a importância da vingança pessoal na novela romântica, no sentido de que este mecanismo narrativo, destaca o individuo, o faz sobressair-se, marcando-o com "relevo próprio"; ao contrário da vingança grupal, que segundo o autor, dissolveria o vingador nas malhas do interesse coletivo. ${ }^{9}$

A narrativa de Hans Staden se encontra implicada tanto na questão grupal, quanto individual da vingança. $O$ viajante é objeto de vingança grupal entre as divergências das tribos, e ao mesmo tempo, o testemunho de sua sobrevivência, é uma prova de sua vingança pessoal diante da adversidade.

Curiosamente, a experiência vertiginosa de Staden, possui muitas coisas em comum, com alguns itens do herói vingador da literatura romântica, conforme observada por Antonio Candido. Tudo começa quando o artilheiro alemão dirige-se em ${ }^{\overline{6}}$ CANDIDO, Antônio. "Da Vingança” .In:Tese e Antítese .SP. Companhia Editora Nacional, 1971.pp.1/29.

${ }^{7}$ Alguns títulos dos ensaios de Candido neste livro, tais como, "Os bichos do subterrâneo", "Catástrofe e sobrevivência" e "O homem dos Avessos", além de uma imagem que evoca um calabouço na novela de Dumas, e que é citada já na primeira página de "Da Vingança", parecem indicar a consciência política do autor, diante da censura militar. Esta escolha, que se dá por uma evocação aparentemente apolítica, ou de cunho apenas literário, revela, no entanto, uma dicção onde as palavras sugerem um duplo sentido. Cf. CANDIDO, Antonio. Op. Cit. passim.

${ }^{8}$ IDEM. p 12.

${ }^{9}$ CANDIDO, Antonio. Op. Cit. p. 13. 
1548 à Lisboa na tentativa de arranjar uma viagem para a Índia, mas acaba por se engajar num navio mercante de um certo capitão Penteado. O navio que viria em busca de pau-brasil, devia também combater o contrabando com mouros da costa africana, apreender navios franceses que disputavam o comércio da madeira de tinta nas costas da terra de Santa Cruz, bem como transportar alguns degredados. ${ }^{10}$

Após muitas peripécias, chegam à Costa de Pernambuco em janeiro de 1549, e logo lhes veio um pedido de ajuda num dos primeiros núcleos de colonização para acudir uma vila sitiada pelos selvagens. Conseguiram quebrar o cerco e reabastecer a vila. Entretanto, na busca de pau-brasil encontraram, na costa da Paraíba, uma nau francesa carregada com a valiosa madeira. Na tentativa de aprisioná-la, perdem o mastro principal, e com algumas baixas, rumam de volta a Portugal, em uma viagem marcada pela fome e pela sede até os Açores, onde reabastecem e seguem viagem para Lisboa, ancorando 16 meses depois. Hans Staden não se deixou abater pelos primeiros infortúnios e já em 1550 encontra-se no navio São Miguel, cujo capitão é João de Salazar, que irá se dirigir em busca do Rio da Prata. Após um motim que foi serenado na altura das ilhas Canárias, próximo a Costa da Guiné, uma tempestade desgarrou a nau capitânia, e no mês seguinte foram atacados por corsários franceses, que levaram todos os bens da tripulação. Empreenderam então a travessia até chegarem à Ilha de Santa Catarina, onde entraram em contato com os primeiros portugueses que lhes deram as coordenadas e a distância para o Sul (Rio da Prata) e para o norte (São Vicente).

A expedição se reorganiza e se divide, deliberando-se que a maioria do grupo se dirigiria para o leste em busca de Assunção no Paraguai, onde já havia um estabelecimento espanhol, enquanto os restantes, entre eles, Staden tentariam navegar para o norte em direção a São Vicente.Nova viagem acidentada: A nave foi forçada pelos ventos, que a despedaçou contra rochedos. Depois os sobreviventes encontraram alguns portugueses que finalmente os encaminharam para São Vicente. E Hans Staden foi engajado como bombardeiro no forte recém construído de Bertioga, na ilha de Santo Amaro. O forte era a guarda de defesa das primeiras povoações em face dos tupinambás, que hostilizavam tanto os portugueses quanto os tupiniquins. Hans Staden,

\footnotetext{
${ }^{10}$ Seguimos aqui as informações do historiador Fernando Novais em ensaio introdutório à nova edição do texto de Hans Staden. Primeiros Registros escritos e ilustrados sobre o Brasil e seus habitantes. SP; Terceiro Nome, 1999.Editada por Mary Lou Paris e Ricardo Othake. Esta edição contém a tradução revisada de Angel Bojadsen feita a partir da edição alemã atualizada por Karl Fouquet em edição da Trauttveter \& Fischer Nachfs; Marburgo de 1981. Esta versão havia também sido publicada originalmente em alemão em 1941, pela sociedade Hans Staden. Cf. NOVAIS, Fernando. O “Brasil” de Hans Staden. Op. Cit.pp 12/25.
} 
durante uma caçada na ilha, foi então feito prisioneiro dos tupinambás, sendo levado primeiro para uma aldeia de Ubatuba, depois para a de Ariró, onde se encontrava o chefe Cunhambebe. ${ }^{11}$ Staden ficou nove meses em cativeiro, onde presenciou as cenas de antropofagia ritual que antecipavam o seu futuro sacrifício. Após uma série de incidentes e tentativas de fuga, conseguiu finalmente ser salvo por um navio mercante francês, até que, em 1555, chegava ao porto de Honfleur, na França.

O interesse da narrativa dos viajantes, tal como a de Staden, não se encontra apenas no propósito de registro histórico, mas em seu caráter de obra com valor em si mesma. Este caráter estranho e extremado, que não provém apenas da descrição das descobertas do novo da paisagem, ou de seus habitantes e costumes ou ainda do próprio medo em face a tudo, essa narrativa trata também da evidenciação do abismo da própria linguagem e da impossibilidade que há nela de se traduzir plenamente a experiência.

À violência avassaladora que fundou e foi definindo os espaços territoriais e as posições sociais durante a época da colonização, foi sendo aderido um processo fragmentário de condicionamentos recíprocos que perduraria até o presente. Sob distintos matizes de interpretação, os intelectuais que se dedicam a analisar a cultura brasileira, volta e meia, esbarram neste paradoxo constitutivo. Segundo o historiador Fernando Novais mesmo havendo enormes variações no processo, o tópico básico e insolúvel é sempre o mesmo:

Realizada a emancipação sob o comando desse senhoriato colonial (senhores das terras e das gentes, ameríndios servilizados ou africanos escravizados) a nação assim criada não pode se identificar com os colonizadores (porque a separação perderia sentido) nem com os colonizados (ameríndios, africanos) porque continua a explorá-los, isto é, a colonizá-los.(...) Daí essa estranha sensação de que estamos desterrados em nossa própria terra, ou de que, aqui, as idéias estão fora do lugar. Se fosse um consolo, caberia lembrar que isto aos olhos dos estrangeiros, que em levas sucessivas (os viajantes no século passado, os brasilianistas no atual) vêm partilhar as nossas perplexidades. ${ }^{12}$

\footnotetext{
${ }^{11}$ Novais pontua que a aldeia de Ariró, do chefe Cunhambebe, talvez fosse próxima de Angra dos Reis, mas a identificação verdadeira ainda é problemática. Cf. NOVAIS, Fernando. Op. Cit, p. 16.

${ }^{12}$ NOVAIS, Fernando. "O 'Brasil' de Hans Staden”. In: STADEN, Hans, séc. 16. Primeiros Registros Escritos e Ilustrados Sobre o Brasil e Seus Habitantes. Tradução de Angel Bojadsen. SP: Editora Terceiro Nome, 1999. P:12. Vale lembrar aqui que Novais na citação acima,(grifo nosso) incorpora textualmente, sem o uso de aspas ou de crédito, a bem conhecida frase com a qual Sérgio Buarque de Holanda inicia o parágrafo de abertura do clássico Raízes do Brasil cuja importância como estudo pioneiro de interpretação histórico-sociológica do país retomamos adiante: "Trazendo de países distantes
} 
Novais destaca a partilha do estrangeiro das nossas próprias perplexidades, como um traço comum que mantêm as bases sobre a qual uma cultura se efetiva e consequentemente, como um dado da estética e das relações políticas que dela advém.

A partilha para os modernistas antropofágicos encontrava-se associada à recuperação dos elementos culturais que iriam que iriam desde hábitos indígenas, até manifestações regionais e populares, que haviam sido escondidos por uma capa embranquecedora pela elite cultural do país.

A imagem de um caldo cultural em ebulição nestas primeiras décadas do século XX, poderia ser regada com o cauim, signo da incorporação da alteridade e aglutinador da experiência de partilha nas culturas indígenas. Essa bebida feita de raízes de mandioca era preparada, segundo dois relatos do período colonial, em diversas etapas. Segundo relato do próprio Staden, da seguinte maneira:

São as mulheres que preparam as bebidas. Usam raízes de mandioca e cozemnas em grandes panelas. Quando está cozido, retiram as mandiocas das panelas, despejam-na em outras panelas ou vasos e deixam que esfrie um pouco. A seguir, meninas sentam-se ao redor e a mastigam, colocam o mastigado num vaso especial. Quando todas as raízes foram mastigadas, colocam o mastigado novamente na panela, despejam água por cima, misturam ambos, e deixam ficar quente de novo. Então há vasos especiais que enterram pela metade dentro da terra e que usam como se usam por aqui barris para vinho e cerveja. Despejam a massa dentro e fecham-nos bem. Então a fermentação ocorre sozinha e a massa fica forte. Deixam-na em repouso durante dois dias. Depois bebem-na e se embriagam.É um líquido espesso e rico. Cada cabana produz a sua própria bebida, e quando uma aldeia inteira quer festejar, o que normalmente ocorre uma vez por mês, vão todos primeiro para uma cabana, bebem tudo que há nela, e assim por diante, até terminarem a bebida de todas as moradias. (...) A bebedeira dura a noite toda. Dançam também entre as fogueiras, soltam berros e sopram em seus instrumentos e fazem uma gritaria medonha quando estão embriagados. Mas é raro que briguem. São muito solidários entre si, o que um tiver a mais de comida que o outro, lhe dá. ${ }^{13}$

nossas formas de convívio, nossas instituições, nossas idéias, e timbrando em manter tudo isso em ambiente muitas vezes desfavorável e hostil, somos ainda hoje uns desterrados em nossa terra." Cf: Buarque de Holanda, Sérgio. Raízes do Brasil. SP: Companhia das Letras, 1995; P 31.

${ }^{13}$ STADEN, Hans. Op. Cit. PP: 98. 
Conforme a descrição do francês Jean de Léry a cauinagem tinha uma estrita relação com a dança:

Mas é principalmente quando emplumados e enfeitados que matam e comem um prisioneiro de guerra em bacanais à moda pagã, de que são sacerdotes ébrios, que se faz interessante vê-los rolar os olhos nas órbitas. Mas também acontece sentarem-se em redes de algodão e uns em frente dos outros beberem modestamente; mas como o seu costume é de se reunirem todos, de um aldeia ou de muitas para beber (o que nunca fazem para comer), esses beberetes especiais são muito raros. Bebam pouco ou muito porém, como não sofrem de melancolia congregam-se todos os dias para dançar e folgar em sua aldeia.(...) não fazem outra coisa todas as noites senão entrar e sair de casa dançando e saltando.(...) Cumpre notar que em todas essas danças, quaisquer que sejam, nunca as mulheres se misturam aos homens; se querem fazem-no em grupo separado. ${ }^{14}$

O preparo do Cauim, atividade feminina na qual a raiz não é digerida, mas acrescida de saliva até sua fermentação, cujo resultado é uma baba embriagante, revela um duplo valor no banquete ritual antropofágico da devoração plena do inimigo fartamente regado pela bebida - uma parte líquida que recusa, e uma outra sólida, que assimila. ${ }^{15}$ Sendo a vingança o grande valor do corpo cultural tupinambá cumpre observar que a repressão imposta ao verdadeiro ritual antropófago gerou transfigurações de ordem mítica e cosmológica ao longo dos séculos de colonização, de tal modo, que segundo o antropólogo Eduardo Viveiros de Castro, os Araweté, uma tribo remanescente dos tupinambás, transpõe o mesmo ímpeto antropofágico em seus discursos sobre o destino póstumo das pessoas. Esta cosmologia fundamentada num devir-outro, sugere a idéia de um corpo que não é definidor de um “eu”, que não é uma "prisão da alma", mas um objeto de devoração que devolve a alma ao mundo. Isso possibilita, "habitar novos corpos e apropriar-se de outros pontos de vista sobre o

\footnotetext{
${ }^{14}$ De LÉRY, Jean.Viagem à terra do Brasil. Belo Horizonte: Itatiaia, 1980.

${ }^{15}$ Esta ambivalência entre assimilação e recusa é detectada por Raúl Antelo na cultura de outros indígenas, os füeguinos, habitantes do extremo sul da Argentina, como parte de um sofisticado jogo cultural de mimetismo. Experts em imitar as expressões dos brancos, tiveram este talento mal interpretado, como sendo uma capacidade adquirida pelo entorno da natureza. Cf: ANTELO, Raúl.."Por um auto-exotismo abismal (na terra do jogo)". In: Transgressão e Modernidade. Ponta Grossa: Editora da UEPG, 2001.
} 
universo. Assim, esse “eu” não pode ser tomado como valor em si, já que seu ideal reside sempre alhures, está sempre projetado na alteridade."16

Aqui se arma todo um ponto nevrálgico, que gera uma perturbação sustentada como o elemento unheimlich ${ }^{17}$ na constituição subjetiva do caráter identitário nacional. Trata-se de um elemento que por força de agrupamento coletivo ou partilha, poderia a primeira vista, produzir a idéia de um "povo brasileiro", sustentado na esperança da formação de um caráter nacional homogêneo. ${ }^{18}$

A intuição da impossibilidade de um grupamento homogêneo de pessoas sob a salvaguarda da idéia de Nação pode ser considerada uma das razões que levaria a geração antropófaga a buscar na mitologia indígena alguns elementos de recusa a um modelo de cultura européia, pelo menos da não euro-atlântica. Esta é a condição sine qua non para o mote cultural da primeira geração de modernistas no país, que iria fundar um modelo irreverente, mas baseado na busca das matrizes históricas de tonalidades híbridas presentes na cultura popular e simultaneamente, criar uma maquinaria de ficção das raízes brasileiras. O regime estético modernista tem sido desde então, sucessivamente problematizado por uma boa parcela das gerações posteriores na arte e na literatura brasileiras. ${ }^{19}$

\footnotetext{
${ }^{16}$ VIVEIROS de CASTRO, Eduardo. “O mármore e a murta: Sobre a inconstância da alma selvagem.”In: A inconstância da alma selvagem.( e outros ensaios de antropologia. SP: Cosac\&Naify, 2002.
}

${ }^{17} 15$ "Chama-se unheimlich tudo que deveria permanecer secreto, escondido e se manifesta". escreve Freud em texto publicado em 1919, e posteriormente como "O estranho" em português; "El sinistro" ao espanhol, "Le inquietante etrangeté" ao francês, e ainda "The uncanny" ao inglês. Trata-se de uma análise de um conto de Hoffmann, "O homem de Areia", onde o psicanalista observa que a operação textual dentro desta narrativa extrapola os limites da ficção codificada, fechada em seu próprio regime, para ir além, ao apresentar o ponto de vista do personagem como realidade possível e não como puro delírio. Algo ao mesmo tempo familiar e inquietante, o unheimlich na leitura freudiana extrai de um estudo sobre o mitológico e literário, elementos que potencializariam a psicanálise ao circundar os limites da representação. FREUD, Sigmund. "O estranho". In: Obras Completas.Vol. XVII. RJ: Imago, 1996.

${ }^{18}$ Embora a consciência da condição colonial em relação à metrópole, esta diferentia specifica - para usar ainda as palavras de Fernando Novais - tenha sido comum a todos os povos de igual formação no Novo Mundo, na América portuguesa foi mais lento, tardio e diluído. Para Novais, "enquanto nas Índias de Castela, os colonos foram desde cedo chamando-se a si próprios de 'criollos' para marcar a distância com os espanhóis metropolitanos, aqui entre nós tudo o que se fazia era chamar 'reinóis' aos nascidos em Portugal. Quer dizer: os hispano-americanos identificavam-se orgulhosamente, por aquilo que eram ou julgavam ser ("nós somos criollos'); os luso-americanos, negativamente, opacamente, por aquilo que julgavam não ser ('não somos reinóis')." Op. Cit. Pg. 13. Novamente aqui percebe-se a forte referência e o uso que faz Novais das idéias de Sérgio Buarque, neste caso, oriundo da temática do "ladrilhadorsemeador", um dos temas de Raízes, no qual recorta epistemologicamente aspectos formativos da América portuguesa em relação a da América hispânica.

${ }^{19}$ Recorde-se que a Semana de Arte Moderna realizada no Teatro Municipal em São Paulo, em 1922, foi um evento seminal no sentido de reunir as novas tendências das expressões literárias, plásticas, arquitetônicas, e musicais em defesa da arte moderna, mas que fosse baseada na realidade brasileiratensionando uma incorporação "antropofágica" das novas formas estéticas propostas pelas vanguardas européias da época, (exemplificados em movimentos como construtivismo, dadaísmo, futurismo, cubismo, entre outros) devidamente mesclados a motivos ou temas da cultura popular local- que iria

DAPesquisa, Florianópolis, v.2, n.4, p. 241-252, 2007. 
A antropofagia tupinambá está longe de deglutir um corpo coisificado, pois em sua ordem cosmológica do sagrado, “a morte em mãos alheias era morte excelente porque era morte vindicável, isto é, justificável e vingável; morte com sentido, produtora de valores e de pessoas, conforme declara o antropólogo Eduardo Viveiros de Castro. ${ }^{20}$

De modo que a vingança não era uma simples decorrência do temperamento agressivo dos índios, ou de uma incapacidade patológica em esquecer e perdoar ofensas passadas, mas, pelo contrário, a vingança, segundo o argumento do antropólogo, era a instituição que justamente promovia a memória. É neste sentido que a memória iria ter uma importante significação no motivo da vingança:

Memória, por sua vez, que não era outra coisa que essa relação ao inimigo, por onde a morte individual punha-se a serviço da longa vida do corpo social. Daí a separação entre a parte do indivíduo e a parte do grupo, a estranha dialética da honra e da ofensa: morrer em mãos alheias era uma honra para o guerreiro, mas um insulto à honra de seu grupo, que impunha resposta equivalente. É que a honra, afinal, repousava em se poder ser motivo de vingança, penhor de perseverar da sociedade em seu próprio devir. O ódio mortal a ligar os inimigos era o sinal de sua mútua indispensabilidade; este simulacro de exocanibalismo consumia os indivíduos para que seus grupos mantivessem o que tinham de essencial: sua relação ao outro, a vingança como conatus vital. A imortalidade era produzida pela vingança, e a busca da imortalidade a produzia. Entre a morte dos inimigos e a própria imortalidade, estava a trajetória de cada um, e o destino de todos. ${ }^{21}$

Assim, para Viveiros de Castro, a vingança era o próprio motor da cultura tupinambá, sendo que antes de qualquer possível incorporação das qualidades do inimigo, argumento aliás, exaustivamente utilizado para interpretar a antropofagia ritual,

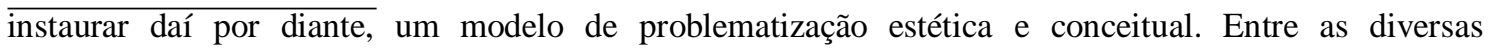
publicações oriundas do movimento da Semana destaca-se a primeira, Klaxon, antecessora de revista Estética e que postulava no primeiro número, ter "uma alma coletiva" em relação aos artigos, poemas, comentários, críticas de arte, piadas e farpas, tão reveladores do estado de espírito dos jovens que elaboraram a ideologia modernista.Renovadora, criativa e abertamente cosmopolita, Klaxon negava a realidade em favor da idéia da arte como expressão cerebral e construtiva, que aparece na seguinte afirmação feita por Mário de Andrade: "KLAXON sabe que a natureza existe. Mas sabe que o moto lírico, produtor da obra de arte, é uma lente transformadora e mesmo deformadora da natureza." Lembremos também que a irreverência e sarcasmo do periódico revela um perfil daquela agressividade tipicamente avant-garde que se confirma nas palavras do poeta Menotti del Picchia: "É uma buzina literária, fonfonando, nas avenidas ruidosas da Arte Nova, o advento da falange galharda dos vanguardistas." O conceito de Antropofagia deriva do periódico mais radical da vanguarda dos anos 20, a Revista de Antropofagia onde já no primeiro número (1928), é publicado o famoso Manifesto Antropófago do poeta Oswald de Andrade.O manifesto, pedra de toque do movimento celebra a "América livre, pura, descolombisada, encantada e bravia", e propõe uma revisão do indianismo romantizado da literatura alencariana e, ao mesmo tempo, uma tentativa de retorno ao primitivo devidamente distanciado dos pressupostos do "Bom Selvagem" na linha enciclopedista de Rousseau.

${ }^{20}$ VIVEIROS de CASTRO, Eduardo. "O mármore e a murta: Sobre a inconstância da alma selvagem."In: A inconstância da alma selvagem.( e outros ensaios de antropologia. SP: Cosac\&Naify, 2002.pp. 181/264.

${ }^{21}$ VIVEIROS de CASTRO. Op. Cit. p. 234.

DAPesquisa, Florianópolis, v.2, n.4, p. 241-252, 2007. 
o que estaria em jogo, seria uma inquieta e radical noção de incompletude, uma indispensabilidade dos outros.

Vale lembrar ainda, que "vingança" é uma palavra que pertence também à constelação semântica ligada ao plantio e à fertilidade, e que tornava-se na cultura tupinambá, o centro da memória coletiva do próprio grupo e do grupo inimigo.

Ainda colocando em discussão retrospectiva a problemática de um ponto de vista estrito à literalidade do canibalismo, sabemos hoje que já na Grécia antiga, o ato de comer carne humana era denominado anthropophagía. E que somente depois da descoberta da América, difundiu-se o termo canibalismo, tendo a origem da palavra uma relação com a primeira viagem de Colombo, quando o navegador torna-se ciente, através dos arawak, que os carib, seus inimigos antropófagos, eram ferozes, bárbaros e conhecidos como cariba. Embora antropófagos e canibais sejam, em princípio, idênticos, há uma importante distinção entre os termos: a antropofagia seria ritual, enquanto o canibalismo ocorreria motivado pela necessidade, pela fome. Essa diferença destaca que o consumo da carne humana como mantimento era mais degradante do que a ingestão segundo regras sociais ${ }^{22}$. Nesse sentido, os antropólogos discordam da variação, pois não há notícias de sociedade que tenha consumido carne humana como alimento. No período colonial brasileiro, foram descritos dois tipos de canibalismo ou antropofagia: o exo-canibalismo, comum entre os tupis, e o endo-canibalismo, praticado, segundo cronistas coloniais, pelos tapuias do nordeste. Esta distinção, feita pelo historiador Ronald Raminelli leva em consideração muitos dos pressupostos de Viveiros de Castro conforme leremos a seguir:

Entre os primeiros, os festins canibais faziam parte da guerra. O prisioneiro era conduzido à aldeia, onde, mais tarde, encontraria a morte em ritual marcado pela vingança e coragem. Logo após a chegada, o chefe designava uma mulher para casar com ele, mas ela não podia afeiçoar-se ao esposo. O dia da execução era uma grande festa. No centro da aldeia, os índios, sobretudo as índias, se alvoroçavam. Os vizinhos também estavam convidados, todos provariam da carne do oponente. No ritual, homens, mulheres e crianças lembravam e vingavam-se dos parentes mortos. Imobilizada, a vítima não esquecia do ímpeto guerreiro: enfrentava com bravura os inimigos e perpetuava o sentimento de vingança. Seus parentes logo o reparariam a sua morte. Essa morte era honrosa, criava elos entre amigos e entre inimigos e identidade entre grupos. Depois de morto, a carne era dividida entre músculos e entranhas. As partes duras eram moqueadas e consumidas pelos homens; mulheres e crianças ingeriam as partes internas cozidas em forma de mingau. $\mathrm{O}$

${ }^{22}$ Cf.RAMINELLI,Ronald . Canibalismo, amor e ódio.In: JBonline.terra.com.br/destaques/500anos/ahtml. 
matador, no entanto, não participava do banquete, entrava em resguardo e trocava de nome. Com a colonização, esse rito foi paulatinamente abandonado, provocando, segundo Eduardo Viveiro de Castro, a perda de uma dimensão essencial da sociedade tupinambá: a identidade. O antropólogo ainda comenta que a repressão ao canibalismo não foi o único motivo para o abandono. Os europeus passaram a ocupar o lugar e as funções dos inimigos, alterando a lógica do ritual. $\mathrm{O}$ endo-canibalismo não se pautava na vingança, mas na ingestão da carne de amigos ou parentes já mortos. Entre os tapuias, não havia melhor túmulo do que as entranhas dos companheiros. Era um ato de amor: mães e pais devoravam seus filhos. Depois de morto, o parente era retalhado e cozido em uma panela. Incineravam os ossos e, em seguida, raspavam-no. Nada era esquecido, nem mesmo o pó que era engolido com água. Os restos eram guardados e consumidos, posteriormente, em solenidades. Ao término do repasto, punham-se a gritar e a chorar. ${ }^{23}$

As diversas leituras, no campo etnográfico, que elaboraram e reelaboraram os rituais antropofágicos, somadas ao deslocamento do assunto para os espaços da literatura e da arte, desenvolvido pelo modernismo brasileiro, resultaram em fértil material para os estudos da cultura, adquirindo desdobramentos, no presente, que incluem a teoria da modernidade.

Neste sentido, com relação aos aspectos culturais enxertados no corpo coletivo desmembrado da modernidade, a ensaísta Ana Luísa Andrade lê a imbricação de um presente devorador, de natureza saturnina, que é ao mesmo tempo, incorporado pelo passado e "que já é fantasma do presente". ${ }^{24}$ Segundo este argumento, a modernidade, ao se realimentar de sua própria linhagem, a assimila, ao mesmo tempo em que se transforma em outra. Por esse motivo, a problemática da temporalidade, através da figura mítica de Saturno, é posta em simetria com o tópico do corpo devorado pela passagem voraz do tempo. Esta condição é exemplificada pela autora, através de uma pintura de Goya, Saturno devorando um de seus filhos, que consistiria efetivamente de uma imagem de um presente devorador corporificado onde,

O abocanhar voraz do filho no passado que desemboca na devoração futura do pai, corpo incorporado que se torna incorporador. A força da linguagem imagística aqui se volta ao acontecimento originário cultural: a representação da espécie animal ampliada no corpo humano que, ao devorar um outro reduzido, apropria-se tanto das forças adversárias (exocanibalismo) quanto das ancestrais (endocanibalismo), canibalismo,

\footnotetext{
${ }^{23}$ RAMINELLI, Ronald. Op. Cit.

${ }^{24}$ ANDRADE, Ana Luísa. "Saturno devorador da Modernidade. Imagens/Sensações".In: Revista Brasileira de Literatura Comparada. Fpolis: Abralic, 1998. pp. 147/160. A partir da imagem de uma pintura de Goya, Saturno devorando seus filhos, a ensaísta estabelece um cruzamento entre os escritos de Benjamin e Clarice Lispector, na ordem do resíduo.
} 
enfim, que antecede a própria linguagem imagística de que é constituída a matéria-prima da pintura. ${ }^{25}$

No ensaio de Ana Luísa, encontra-se também uma referência ao pensamento de Walter Benjamin, que, segundo a autora, já é, por sua vez, saturninamente reproduzido a partir de fragmentos de "um corpo arcaico desmembrado", potencializador das alegorias modernas. ${ }^{26}$ Assim, de uma memória cultural fragmentada, o retorno de certas imagens, como aquelas produzidas pelo nosso movimento modernista que havia incorporado procedimentos similares aos do surrealismo, as fecundas reicorporações da arte brasileira desde a virada modernista antropofágica arma um modelo estético e político e coloca ainda em funcionamento, aquela espécie de "penhor da sociedade em seu próprio devir", que conforme o argumento de Viveiros de Castro, é fundador por excelência, do motivo da vingança nas sociedade tupinambá, mas que metaforicamente propõe um regime estético e conceitual para nosso país.

\footnotetext{
${ }^{25}$ Idem. p. 148.

${ }^{26}$ Ibidem. p. 150.
} 